\title{
Blood and plasma donors during the COVID-19 pandemic: arguments against financial stimulation
}

\author{
Laura Pricop ${ }^{1}$ (D)
}

Received: 5 November 2020 / Accepted: 15 February 2021 / Published online: 23 February 2021 (C) Springer Nature Switzerland AG 2021

\begin{abstract}
During the COVID-19 pandemic, blood and convalescent plasma donors are dearly needed. There is a need to modify donor recruitment strategies in order to stimulate these donors. Financial stimulants though, cannot be possibly used. This paper will analyze, from an ethical perspective, the possible consequences regarding the blood and plasma donor system by a simple shift of attention from the voluntary unpaid donor to the paid one or the blood seller.
\end{abstract}

Keywords Voluntary unpaid donor - Convalescent plasma $\cdot$ Supererogation · Rational altruism · Utilitarianism

A crisis always requires new measures and policies. ${ }^{1}$ Prior to the pandemic, all hospitals were frequently facing the lack of either blood or plasma, the COVID-19 crisis made this situation dramatic. The population is not motivated enough to enter a hospital environment anymore. Calls for blood and convalescent plasma donations are not answered. ${ }^{2}$ This reticent and prudent reaction is due to fear of contamination,

\footnotetext{
${ }^{1}$ This note belongs to the Topical Collection"Seeing Clearly Through COVID-19: Current and future questions for the history and philosophy of the life sciences", edited by G. Boniolo and L. Onaga.

2 The convalescent plasma therapy, viewed as a possible treatment for those affected with SARS-COV2, assumes to transfer of passive immunity from recovered individuals to active patients (Sahu et al. 2020). According to these authors, this therapy is quite difficult to apply at a large scale, first, it requires a full donor-patient match, as well as sufficient antibodies present in the blood. Other researchers (Duan et al. 2020 and Liu et al. 2020) outline that, in the case of COVID-19 patients, this therapy has negative effects, thus recommending utmost care in its use.
}

Laura Pricop

laura.pricop@gmail.com

1 Institute for Interdisciplinary Research, Alexandru Ioan Cuza University of Iași, Social Sciences and Humanities Research Department, Iași, Romania 
insecurity, and national guidelines recommending people to stay at home as much as possible.

In this period of crisis, besides the current need for blood donations and blood components, there is also the need of convalescent plasma donations. No health system or service for private or public health has taken into consideration a new protocol of action that will permit sufficient blood and plasma collections to cover the needs of patients. Even though the procedures for collecting blood components (red cells, white platelets, and plasma) and convalescent plasma (used for antibody therapy) are similar, they are catered for different categories of diseases. Furthermore, blood requires specialized storage. Normal blood cannot be stored for more than 42 days and plasma cannot be stored for more than 1 year. It is difficult to form a unified clinical convention since the blood or plasma may be needed in the field of oncology or blood disorders. These people require donations coming from a healthy populace. Convalescent plasma donors are likely people who have just gone through a very difficult or at least stressful situation. They are vulnerable persons which are asked to donate convalescent plasma. The European Commission (2020) has built up a 40 million euro budget which has been given to member states to acquire plasmapheresis equipment. Unfortunately, the entire system is based on the goodwill of donors. Thus, public health systems are not ready yet to work on automated pilot.

The fact that blood and plasma collection services work on two different channels, based on different ethical principles and values, has made this a very difficult situation. Most services of blood and plasma collection are based on voluntary unpaid donations. While others, on paid donations and also voluntary unpaid donations. In the case of plasma donations, the majority of members state EU prefers voluntary unpaid donors with the exception of Germany, the Czech Republic, Hungary, and Austria. ${ }^{3}$ These countries collect plasma from paid donors as well. Countries such as the United Kingdom of Britain and Portugal normally import from the United States of America all the required plasma. Unfortunately, in this chain, US plasma donors are commonly paid.

Moral duplicity is present at the different levels in which plasma and blood are acquired. For example, for a EU member state, convalescent plasma and blood components may be obtained from voluntary unpaid donors, paid donors, or imported from other countries where this really starts working as a business. The European legislation, through Directive 2002/98/EC, Article 20 leaves all these possibilities open. In this pandemic, the moral deficit that has been quietly accepted is now close to becoming a norm. Moral principles and current regulations have been re-interpreted, blood and plasma donations are slowly transforming into a market.

The act of donation is governed by a golden rule. As pointed out by Singer (2009, p.16), this rule requires to approach the wishes, needs, and sufferings of others as being our own. Poverty, sickness, and death are calamities which can also be addressed through acts of kindness but which are not necessarily free of charge.

\footnotetext{
3 Principles of voluntary donor services are based on: the anonymity of both donor and recipient, the benevolence of the donor, and absence of profit on the part of the establishments involved in blood transfusion services. The Definition adopted at an EU level through the 2002/98/EC Directive.
} 
The person who wants to help has to offer something to prevent a difficult situation for another person. The golden rule asserts that we have a strong moral obligation towards our human fellows. The act of donation does not enter the category of compulsory actions. The act of donating something to a stranger belongs to the category of supererogatory or altruistic actions. ${ }^{4}$

Paid blood and plasma donation may be considered as a useful action. Yet, can this paid action still be viewed as an act of donation? The crisis imposed by the COVID-19 pandemic shifted the attention towards paid blood and plasma donations. Can utilitarianism offer an answer to such an issue $?^{5}$ Maintaining a minimalistic explicative line, this simplification deprives the principle of utility of its moral values. Utilitarianism is unable of rendering objective the action of paid blood donation. Trying to objectify such an action would assume the presence of a regulator between the persons involved in the exchange. This regulator would limit the impulses of the giver and receiver. Such a regulation should be applied to the majority, and its objectification would establish that each blood/plasma donor must be paid.

The recent history of medicine and philosophy of medicine registered sustained efforts for prohibiting and reducing blood selling and buying. The most important arguments, which actually improved the British and American systems, were provided by Richard Titmuss. The British social scientist showed that blood cannot be considered to be wares and that no price can be established for it on the basis of demand. Altruism would be put to an end otherwise. To consider blood components as goods would mean to legalize hostility between doctor and patient. This will increase the danger of unethical behavior of medical science and practice. It will result in situations in which blood will be delivered only by the poor or the jobless (Titmuss 1997, p. 314). The crisis brought about by COVID-19 pandemic and the need of convalescent plasma does not justify the measures taken by certain governmental authorities. Specifically, offering money for blood and convalescent plasma donations. Such measures only hinder the progress done over the last decades. From an ethical perspective, this is regressive behavior. The institutions allocating and offering money to blood or convalescent plasma donors make a serious error of moral judgment. This affects the medical system heavily. Lastly, due to money reward conditioning, the very concepts of altruism, benevolence and goodwill manifested to strangers are being tainted.

\footnotetext{
4 The supererogatory action is required in an imperative situation, involving exclusively the intervention of the person who considers that it is his/ her moral duty to take action here and now. An altruistic action develops a different relation with time, affecting both the present and the future. Such a relation of altruism with time and prudent calculation, intervening in the interpretation of an action, makes us think of rational altruism.

5 In the field of public health, this principle is prioritary versus other ethical principles. In the case of pandemic, the lockdown is ethically justified by this principle, as it aims to do good to the population, to the majority of people, and not to certain individuals. At the level of public health policies, the principle of utility appears as a cost-benefit calculation. Another utilitarian calculation refers to the allocation of resources to those with the highest survival rate.
} 
By doing good to an unknown person, the stranger will be forced to pay an underlying price. This price will be ever increasing to the point that the stranger will be transformed into an enemy. Such practices will make an environment where blood and plasma will be ruled by supply and demand. If this new blood components market will not meet the demand, these will be procured off the black market. In contrast, if there will be a surplus, valuable resources will be wasted. That is because blood cannot be held in storage for more than 42 days. The way in which it is stored also requires special conditions and most blood components have a limited shelf life.

The moral alternative would assume educating the population to understand rational altruism. To be encouraged to care for others not just for oneself. Neither blood nor the organs harvested from people can be dealt with as wares. Otherwise, that would mean risking commercial exploitation and depersonalization of individuals.

\section{References:}

Duan, K., Liu, B., Li, C., Zhang, H., Yu, T., Qu, J., Zhou, M., Chen, L., Meng, S., Hu, Y., Peng, C., Yuan, M., Huang, J., Wang, Z., Yu, J., Gao, X., Wang, D., Yu, X., Li, L., .. Yang, X. (2020). Effectivnnes of convalescent plasma therapy în severe COVID-19 patients. Proceedings of the National Academy of Sciences, 117(17), 9490-9496. https://doi.org/10.1073/pnas.2004168117

European Commission. (2020). Coronavirus: European commission strengthens support for treatment through convalescent plasma. ec.europa.eu/commision/presscorner/detail/en/ip-20-1435

Liu, M., Chen, Z., Dai, M. Y., Yang, J. H., Chen, X. B., Chen, D., You, H., Guo, X., Leng, Y., Yu, L., Zhang, M. L., Wu, X., Yang, J., Gao, C., Tenen, G. D., Chai, L., \& Ai, F. (2020). Lessons learned from early compassionate use of convalescent plasma on critically ill patients with COVID-19. Transfusion, 60, 2210-2216. https://doi.org/10.1111/trf.15975

Singer, P. (2009). The life you can save. How to play your part in ending world poverty. Picador.

Sahu, K. K., Raturi, M., Siddiqui, A. D., \& Cerny, J. (2020). Because Every Drop Counts: Blood donation during the COVID-19 Pandemic. Transfusion clinique et biologique: journal de la Societe francaise de transfusion sanguine, 27(3), 105-108. https://doi.org/10.1016/j.tracli.2020.06.009

Titmuss, R. (1997). The gift relationship: from human blood to social policy. Edited by Ann Oakley and John Ashton. New York: The New Press.

Publisher's Note Springer Nature remains neutral with regard to jurisdictional claims in published maps and institutional affiliations. 